\title{
First report of Cryptosporidium canis in farmed Arctic foxes (Vulpes lagopus) in China
}

\author{
Xiao-Xuan Zhang ${ }^{1,2+}$, Wei Cong ${ }^{1,2+}$, Jian-Gang Ma' ${ }^{1}$ Zhi-Long Lou ${ }^{1,2}$, Wen-Bin Zheng ${ }^{1}$, Quan Zhao ${ }^{2}$ \\ and Xing-Quan Zhu, ${ }^{1,2^{*}}$
}

\begin{abstract}
Background: Cryptosporidium is an important genus of enteric zoonotic parasites, which can infect a wide range of animals including foxes. Little information is available concerning the prevalence and molecular characterisation of Cryptosporidium spp. in farmed Arctic foxes (Vulpes lagopus) in China. Thus, the objective of the present study was to investigate the prevalence of Cryptosporidium spp. in Arctic foxes in China using nested PCR amplification of the small subunit ribosomal RNA (SSU rRNA) gene.

Findings: The overall prevalence of Cryptosporidium spp. in Arctic foxes was $15.9 \%$ (48/302), with $12.9 \%$ in male $(18 / 139)$ and $18.4 \%$ in female (30/163) foxes, respectively. The prevalence in different farms varied from 0 to $31.43 \%$. The prevalence of infection in different age groups varied from $14.1 \%$ to $19.0 \%$. Foxes from Hebei Province $(7.8 \%, 11 / 141)$ had a significantly lower Cryptosporidium spp. prevalence than those from Heilongjiang Province $(22.9 \%, 16 / 70)$ and Jilin Province $(23.1 \%, 21 / 91)(P=0.0015)$. Sequence analysis of the SSU rRNA gene indicated that all the 48 isolates represented C. canis.
\end{abstract}

Conclusions: This is the first report of C. canis infection in farmed Arctic foxes in China, which also provides foundation data for preventing and controlling Cryptosporidium infection in foxes, other animals and humans.

Keywords: Cryptosporidium canis, Prevalence, Arctic fox, China

\section{Findings}

\section{Background}

Cryptosporidiosis is caused by species of Cryptosporidium, important zoonotic protozoan parasites [1-3]. Cryptosporidium spp. not only have a cosmopolitan distribution but can also infect a wide range of animals including foxes [1, 4]. Humans and animals are often infected through faecal-oral route and infection can result in acute or chronic diarrhea and even death $[3,5]$. So far, more than 17 Cryptosporidium species/genotypes, such as $C$. andersoni, $C$. parvum, $C$. hominis, C. meleagridis, C. felis, C. canis, C. muris, C. suis

\footnotetext{
*Correspondence: xingquanzhu1@hotmail.com

${ }^{\dagger}$ Equal contributors

'State Key Laboratory of Veterinary Etiological Biology, Key Laboratory of Veterinary Parasitology of Gansu Province, Lanzhou Veterinary Research Institute, Chinese Academy of Agricultural Sciences, Lanzhou, Gansu Province 730046, PR China

${ }^{2}$ College of Animal Science and Technology, Jilin Agricultural University, Changchun, Jilin Province 130118, PR China
}

and Cryptosporidium sp. deer genotype, have been identified in humans [6-10], but only C. parvum, Cryptosporidium sp. muskrat genotype II and C. canis have been found in foxes $[6,11,12]$.

The Arctic fox (Vulpes lagopus) is common in the Arctic regions [4], and has been imported to China from the former Soviet Union in the 1950s [13]. In China, with the improvement of living standards, Arctic foxes were commonly raised by farmers to provide furs for humans. More importantly, because of the close relationship between farmed foxes and humans, foxes can transfer indirectly or directly many pathogens to humans, such as T. gondii [14]. Some studies concerning Cryptosporidium spp. infections in foxes have been reported $[4,6,12,15]$, but no such information about Cryptosporidium spp. prevalence in foxes is available in China. The objective of the present study was to estimate the prevalence of Cryptosporidium infection in farmed foxes in China, for the first time. 


\section{Methods}

\section{Ethics statement}

This study was approved by the Animal Ethics Committee of Lanzhou Veterinary Research Institute, Chinese Academy of Agricultural Sciences (Approval No. LVRIAEC2013010). The Arctic foxes from which the faeces were collected, were handled in accordance with good animal practices required by the Animal Ethics Procedures and Guidelines of the People's Republic of China.

\section{Specimen collection}

A total of 302 faecal samples from 91 foxes in Jilin Province, from 70 foxes in Heilongjiang Province, and from 141 foxes from Hebei Province, were collected in 2014. All foxes were in good health during the sampling time. Fresh faecal samples were collected from each animal using sterile gloves immediately after the defecation onto the ground and transported to the laboratory. Information regarding geographical origin, gender and age of the foxes were acquired by a questionnaire.

\section{DNA extraction and PCR amplification}

Genomic DNA was extracted from faeces using an EZNAR Stool DNA kit (OMEGA, USA) following the manufacturer's instructions and stored at $-20{ }^{\circ} \mathrm{C}$ until PCR analysis. Cryptosporidium species/genotypes were identified by nested PCR amplification of the small subunit ribosomal RNA (SSU rRNA) gene [3]. Every amplification included positive and negative controls. Amplification products were visualised on $1.5 \%$ agarose gels containing GoldView ${ }^{\mathrm{TM}}$ (Solarbio, China).

\section{Sequencing and phylogenetic analyses}

Positive secondary PCR products from foxes were sequenced by the Genscript Company (Nanjing, China). Cryptosporidium species/genotypes were identified by comparison with reference sequences using BLAST (http:// www.ncbi.nlm.nih.gov/BLAST/) and computer program
Clustal X 1.83. Phylogenetic relationships of Cryptosporidium spp. were reconstructed using Neighbour-Joining (NJ) method implemented in Mega 5.0 (Kimura 2-parameter model, 1,000 replicates). All representative nucleotide sequences obtained were deposited in the GenBank under accession numbers KU215430-KU215436.

\section{Statistical analysis}

The variation in Cryptosporidium spp. prevalence $(y)$ in foxes in relation to geographical location $(x 1)$, gender $(x 2)$ and age $(x 3)$ were analysed by $x^{2}$ test using SAS version 9.1 (SAS Institute Inc., USA). Using multivariable regression analysis each of these variables was included in the binary Logit model as an independent variable. The best model was identified by Fisher's scoring algorithm. All tests were two-sided. Results were considered statistically significant at $P<0.05$. Odds ratios (ORs) with $95 \%$ confidence intervals $(95 \% \mathrm{CI})$ were also calculated.

\section{Results and discussion}

A total of 48 out of 302 Arctic foxes (15.9\%) were tested Cryptosporidium-positive by nested PCR amplification of the SSU rRNA gene (Table 1). The prevalence in different farms varied from 0 to $31.4 \%$ (data not shown). Cryptosporidium spp. prevalence was $14.1 \%$ (9/64) in pre-weaned foxes, $15.6 \%(28 / 180)$ in young foxes, and $19.0 \%(11 / 58)$ in adult foxes (Table 1). The prevalence in different regions varied between $7.8-23.1 \%$ (Table 1 ). Moreover, female foxes $(18.4 \%, 30 / 163)$ had a higher Cryptosporidium prevalence than males (12.9\%, 18/ 139), although the differences were not significant (Table 1). Sequence analysis of the SSU rRNA gene indicated that all of the 48 isolates represented $C$. canis (Fig. 1).

In the present study, the overall Cryptosporidium spp. prevalence was $15.9 \%$ (95 \% CI 11.8-20.0) (Table 1), which was higher than that in wild Arctic foxes in the central Canadian Arctic (9\%) [4], wild foxes in wetlands

Table 1 Prevalence of Cryptosporidium canis in farmed foxes in Jilin, Heilongjiang and Hebei Provinces, northern China

\begin{tabular}{|c|c|c|c|c|c|c|}
\hline Factor & Category & No. of tested & No. of positive & Prevalence (\%) (95 \% Cl) & Odds Ratios (OR) (95 \% Cl) & $P$-value \\
\hline \multirow[t]{3}{*}{ Region } & Hebei Province & 141 & 11 & $7.8(3.4-12.2)$ & Reference & 0.0015 \\
\hline & Heilongjiang Province & 70 & 16 & $22.9(13.0-32.7)$ & $3.5(1.5-8.0)$ & \\
\hline & Jilin Province & 91 & 21 & $23.1(14.4-31.7)$ & $3.6(1.6-7.8)$ & \\
\hline \multirow[t]{2}{*}{ Gender } & Male & 139 & 18 & $12.9(7.4-18.5)$ & Reference & 0.1962 \\
\hline & Female & 163 & 30 & $18.4(12.5-24.4)$ & $1.5(0.8-2.9)$ & \\
\hline \multirow[t]{3}{*}{ Age } & Pre-weaned & 64 & 9 & $14.1(5.6-22.6)$ & Reference & 0.7463 \\
\hline & Young & 180 & 28 & $15.6(10.3-20.9)$ & $1.1(0.5-2.5)$ & \\
\hline & Adult & 58 & 11 & $19.0(8.9-29.1)$ & $1.4(0.6-3.8)$ & \\
\hline Total & & 302 & 48 & $15.9(11.8-20.0)$ & & \\
\hline
\end{tabular}




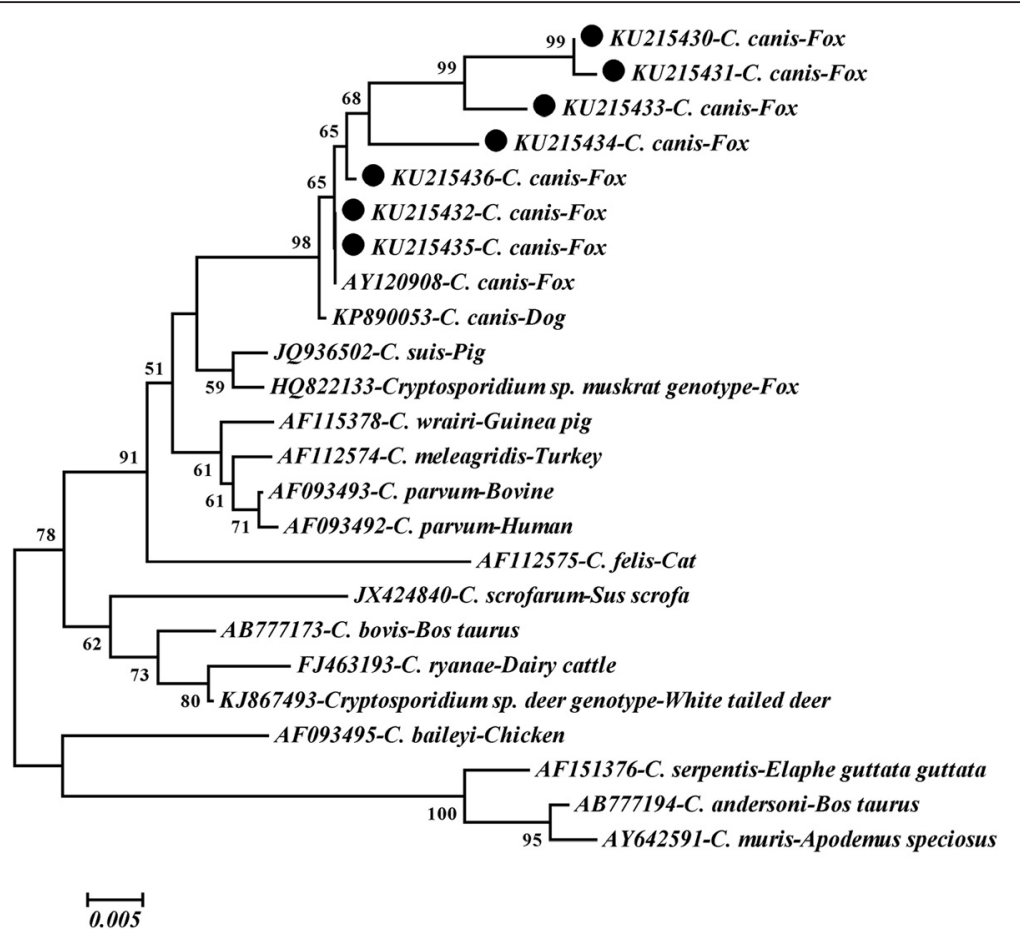

Fig. 1 Phylogenetic analysis of Cryptosporidium canis using Neighbour-Joining (NJ) method based on sequences of the small subunit ribosomal RNA (SSU rRNA) gene. Bootstrap values $>50 \%$ are shown. Isolates of $C$. canis identified in the present study are indicated by a solid circle

adjacent to the Chesapeake Bay, USA (8 \%) [6], wild red foxes in Ireland (1.6 \%) and Warwickshire, UK (8.7\%) [12], and Norway (2.2\%) [16], but lower than that in red foxes in the Slovak Republic (38.7\%) [11]. These differences might be related to the detection methods, age distribution of the samples, the timing of sample collection, sample sizes and geo-ecological conditions in the investigation regions.

The effects of geographical location, gender and age were analysed using univariate analysis. The impacts of multiple variables on the prevalence of $C$. canis were evaluated by forward stepwise logistic regression analysis using Fisher's scoring technique. In the final model, only one variable had a significant effect, described by the equation $y=0.5964 x 1+0.4646$. Region of origin has a positive effect on the risk of $C$. canis ( $\mathrm{OR}=1.8,95 \% \mathrm{CI}$ 1.3-2.6). Foxes collected from the Jilin Province (23.1\%. $\mathrm{OR}=3.6,95 \% \mathrm{CI}$ 1.6-7.8) and Heilongjiang Province (22.9\%, OR $=3.5,95 \%$ CI 1.5-8.0) were found to be more susceptible than those collected from the Hebei Province $(7.8 \%, 95 \%$ CI 3.4-12.2, $P=0.0015)$ (Table 1).

Three Cryptosporidium species/genotypes (C. parvum, C. canis and Cryptosporidium sp. muskrat genotype II) have been found in foxes $[4,6,12,15]$. Of these, C. parvum and $C$. canis have also been reported in humans $[17,18]$ suggesting that foxes could be a potential resource for humans acquiring cryptosporidiosis. In the present study, all of the 48 Cryptosporidium-positive samples represented
C. canis (Fig. 1), which was similar to previous studies showing that $C$. canis is more prevalent in foxes $[4,6,11,16]$. However, probably due to the smaller sample sizes, $C$. parvum and Cryptosporidium sp. muskrat genotype II were not found in the present study.

\section{Conclusions}

The results of the present study indicated the existence $(15.9 \%, 48 / 302)$ of C. canis infections in farmed Arctic foxes in northern China. Logistic regression analysis indicated that region was the significant risk factor shown by this study for Cryptosporidium spp. infection in the foxes examined. The data could provide a foundation for the prevention and control of Cryptosporidium spp. infections in foxes, other animals and humans.

\section{Competing interests}

The authors declare that they have no competing interests.

\section{Authors' contributions}

$X Q Z$ and $X X Z$ conceived and designed the study and critically revised the manuscript. XXZ, WC, JGM and ZLL performed the experiments. XXZ and WC analysed the data. XXZ drafted the manuscript. WBZ and QZ helped in study design and implementation. All authors read and approved the final manuscript.

\section{Acknowledgements}

Project support was provided by the National Key Project of Scientific and Technical Supporting Program (Grant No. 2012BAD12B07) and the Science Fund for Creative Research Groups of Gansu Province (Grant No. 1210RJIA006). 
Received: 24 December 2015 Accepted: 20 February 2016

Published online: 03 March 2016

\section{References}

1. Kaupke A, Rzeżutka A. Emergence of novel subtypes of Cryptosporidium parvum in calves in Poland. Parasitol Res. 2015;114:4709-16.

2. Liu A, Zhang J, Zhao J, Zhao W, Wang R, Zhang L. The first report of Cryptosporidium andersoni in horses with diarrhea and multilocus subtype analysis. Parasit Vectors. 2015;8:483.

3. Qin SY, Zhang XX, Zhao GH, Zhou DH, Yin MY, Zhao Q, et al. First report of Cryptosporidium spp. in white yaks in China. Parasit Vectors. 2014;7:230

4. Elmore SA, Lalonde LF, Samelius G, Alisauskas RT, Gajadharb AA, Jenkins EJ. Endoparasites in the feces of arctic foxes in a terrestrial ecosystem in Canada. Int J Parasitol. 2013;2:90-6.

5. Wang T, Chen Z, Xie Y, Hou R, Wu Q, Gu X, et al. Prevalence and molecular characterization of Cryptosporidium in giant panda (Ailuropoda melanoleuca) in Sichuan province, China. Parasit Vectors. 2015;8:344.

6. Zhou L, Fayer R, Trout JM, Ryan UM, Schaefer 3rd FW, Xiao L. Genotypes of Cryptosporidium species infecting fur-bearing mammals differ from those of species infecting humans. Appl Environ Microbiol. 2004;70:7574-7.

7. Ong CS, Eisler DL, Alikhani A, Fung WW, Tomblin J, Bowie WR, et al. Novel Cryptosporidium genotypes in sporadic cryptosporidiosis cases: first report of human infections with a cervine genotype. Emerg Infect Dis. 2002;8:263-8.

8. Xiao L, Bern C, Arrowood M, Sulaiman I, Zhou L, Kawai V, et al. Identification of the Cryptosporidium pig genotype in a human patient. J Infect Dis. 2002; 185:1846-8.

9. Xiao L, Bern C, Limor J, Sulaiman I, Roberts J, Checkley W, et al. Identification of 5 types of Cryptosporidium parasites in children in Lima, Peru. J Infect Dis. 2001;183:492-7.

10. Ehsan AM, Geurden T, Casaert S, Parvin SM, Islam TM, Ahmed UM, et al. Assessment of zoonotic transmission of Giardia and Cryptosporidium between cattle and humans in rural villages in Bangladesh. PLoS One. 2015; 10:e0118239.

11. Ravaszova P, Halanova M, Goldova M, Valencakova A, Malcekova B, Hurníková Z, et al. Occurrence of Cryptosporidium spp. in red foxes and brown bear in the Slovak Republic. Parasitol Res. 2012;110:469-71.

12. Nagano $Y$, Finn MB, Lowery CJ, Murphy T, Moriarty J, Power E, et al. Occurrence of Cryptosporidium parvum and bacterial pathogens in faecal material in the red fox (Vulpes vulpes) population. Vet Res Commun. 2007; 31:559-64.

13. Zhang PY. The approach of fox species devolution and measures for development in China. Ani Sci \& Vet Med. 2001;18:71-2 (In Chinese).

14. Prestrud KW, Dubey JP, Asbakk K, Fuglei E, Su C. First isolate of Toxoplasma gondii from arctic fox (Vulpes lagopus) from Svalbard. Vet Parasitol. 2008;151: 110-4.

15. Sturdee AP, Chalmers RM, Null SA. Detection of Cryptosporidium oocysts in wild mammals of mainland Britain. Vet Parasitol. 1999:80:273-80.

16. Hamnes IS, Gjerde BK, Forberg T, Robertson L. Occurrence of Giardia and Cryptosporidium in Norwegian red foxes (Vulpes vulpes). Vet Parasitol. 2007; 143:347-53.

17. Adamu H, Petros B, Zhang G, Kassa H, Amer S, Ye J, et al. Distribution and clinical manifestations of Cryptosporidium species and subtypes in HIV/AIDS patients in Ethiopia. PLoS Negl Trop Dis. 2014;8:e2831.

18. Kinross P, Beser J, Troell K, Axén C, Björkman C, Lebbad M, et al. Cryptosporidium parvum infections in a cohort of veterinary students in Sweden. Epidemiol Infect. 2015;143:2748-56.

\section{Submit your next manuscript to BioMed Central and we will help you at every step:}

- We accept pre-submission inquiries

- Our selector tool helps you to find the most relevant journal

- We provide round the clock customer support

- Convenient online submission

- Thorough peer review

- Inclusion in PubMed and all major indexing services

- Maximum visibility for your research

Submit your manuscript at www.biomedcentral.com/submit 